\title{
Intracerebroventricular infusion of vasoactive intestinal peptide rescues the luteinizing hormone surge in middle-aged female rats
}

\author{
Yan Sun ${ }^{1}$, Jun Shu ${ }^{1}$, Kwame Kyei ${ }^{1}$ and Genevieve S. Neal-Perry ${ }^{1,2}$ * \\ 1 Department of Obstetrics/Gynecology and Women's Health, Albert Einstein College of Medicine, Bronx, NY, USA \\ 2 Dominick P. Purpura Department of Neuroscience, Albert Einstein College of Medicine, Bronx, NY, USA
}

\section{Edited by:}

Henryk Urbanski, Oregon National Primate Research Center, USA

\section{Reviewed by:}

Xavier Bonnefont, CNRS, France Jonny St-Amand, Laval University Medical Center, Canada

*Correspondence:

Genevieve S. Neal-Perry, Department of Obstetrics/Gynecology and Women's Health, Albert Einstein College of Medicine, 1300 Morris Park Avenue, U1211, Bronx, NY 10461, USA.

e-mail: sienna3598@aol.com
Reproductive aging is characterized by delayed and attenuated luteinizing hormone (LH) surges apparent in middle-aged rats. The suprachiasmatic nucleus (SCN) contains the circadian clock that is responsible for the timing of diverse neuroendocrine rhythms. Electrophysiological studies suggest vasoactive intestinal peptide (VIP) originating from the SCN excites gonadotropin-releasing hormone $(\mathrm{GnRH})$ neurons and affects daily patterns of $\mathrm{GnRH}-\mathrm{LH}$ release. Age-related LH surge dysfunction correlates with reduced VIP mRNA expression in the SCN and fewer GnRH neurons with VIP contacts expressing c-fos, a marker of neuronal activation, on the day of the LH surge. To determine if age-related LH surge dysfunction reflects reduced VIP availability or altered VIP responsiveness under estradiol positive feedback conditions, we assessed the effect of intracerebroventricular (icv) VIP infusion on c-fos expression in $\mathrm{GnRH}$ neurons and on $\mathrm{LH}$ release in ovariohysterectomized, hormone-primed young and middle-aged rats. Icv infusion of VIP between 1300 and $1600 \mathrm{~h}$ significantly advanced the time of peak $\mathrm{LH}$ release, increased total and peak $\mathrm{LH}$ release, and increased the number of $\mathrm{GnRH}$ neurons expressing c-fos on the day of the LH surge in middle-aged rats. Surprisingly, icv infusion of VIP in young females significantly reduced the number of $\mathrm{GnRH}$ neurons expressing c-fos and delayed and reduced the $\mathrm{LH}$ surge. These observations suggest that a critical balance of VIP signaling is required to activate $\mathrm{GnRH}$ neurons for an appropriately timed and robust $\mathrm{LH}$ surge in young and middle-aged females. Age-related LH surge changes may, in part, result from decreased availability and reduced VIP-mediated neurotransmission under estradiol positive feedback conditions.

Keywords: vasoactive intestinal peptide, luteinizing hormone, gonadotropin-releasing hormone, aging

\section{INTRODUCTION}

An appropriately timed and robust preovulatory gonadotropinreleasing hormone (GnRH)-luteinizing hormone (LH) surge in rodents requires the convergence of synchronized neurochemical and hormonal events. Female reproductive aging is characterized by reduced responsiveness to estrogen positive feedback, resulting in a delayed and attenuated preovulatory LH surge (Cooper et al., 1980; Wise, 1982). Age-related changes in the magnitude of the LH surge reflect dysregulation of estradiol-regulated hypothalamic neurotransmission, which includes increased inhibitory input from GABA, reduced excitatory input from glutamate and kisspeptin, and reduced insulin-like growth factor-1 signaling (Neal-Perry et al., 2008, 2009; Lederman et al., 2010; Todd et al., 2010; Sun et al., 2011).

The suprachiasmatic nucleus (SCN) is hypothesized to integrate and synchronize all of the diverse neuroendocrine events required to activate $\mathrm{GnRH}$ neurons and to initiate an appropriately timed GnRH-LH surge (Brown-Grant and Raisman, 1977; Wiegand and Terasawa, 1982; Van der Beek et al., 1997; Colwell et al., 2003; de la Iglesia and Schwartz, 2006). Vasoactive intestinal peptide (VIP) neurons and vasopressin (AVP) positive cells located in the ventrolateral and dorsomedial SCN (Card et al., 1988) are hypothesized to be principal mediators of SCN modulation of the LH surge (van der Beek et al., 1993, 1994; Palm et al., 1999; Miller et al., 2006; Tsukahara, 2006). Moreover, available data suggest that a critical level of AVP and VIP signaling are required for appropriately timed LH pulse frequencies and induction of the LH surge under estradiol positive feedback conditions (Alexander et al., 1985; Harney et al., 1996; Krajnak et al., 1998; Palm et al., 1999; Colwell et al., 2003; Miller et al., 2006). Consistent with this hypothesis, icv infusion of AVP rescued LH release in transgenic mice with a mutation in the core circadian gene CLOCK and rescues the amplitude of the LH surge in rats that have AVP lesions in the SCN. Moreover VIP neurons located in the SCN project to GnRH neurons (Van der Beek et al., 1997), VIP activates GnRH neurons in a time- and estradiol-dependent fashion (van der Beek et al., 1994; Krajnak et al., 2001; Christian and Moenter, 2008), and VIP receptors are expressed on GnRH neurons and on astrocytes that are in close apposition to and ensheath GnRH neurons (Smith et al., 2000; Gerhold and Wise, 2006). 
Additionally, exogenous infusion of VIP into the brain induces GnRH (Samson et al., 1981) and LH release in estradiol-primed females with SCN lesions (Palm et al., 1999). Conversely, intracerebroventricular (icv) infusion of VIP antiserum in intact females or VIP infusion in ovariectomized females blunts the LH surge and LH pulses, respectively (Alexander et al., 1985; Weick and Stobie, 1992, 1995).

Of interest, changes in the LH surge in old, irregularly cycling and persistent diestrus female rats correlate with reduced $\mathrm{c}$-fos expression in SCN neurons, reduced VIP mRNA expression in the SCN, and reduced activation of GnRH neurons receiving VIP contacts (Krajnak et al., 1998, 2001). Additionally, the LH surge in young rats is delayed and attenuated by infusion of VIP antiserum into the third ventricle (van der Beek et al., 1999), infusion of VIP antisense oligonucleotides into the SCN (Harney et al., 1996), or thermal ablation of VIP neurons in the SCN (van der Beek et al., 1993). In contrast AVP mRNA expression in the SCN of reproductively aging females does not change (Krajnak et al., 1998). These data led us to hypothesize that the delayed and attenuated LH surge in regularly cycling, middle-aged rats results from reduced responsiveness to VIP, and/or reduced availability of VIP at the time of the surge. To test this hypothesis we (1) determined if hypothalamic VIP mRNA levels in regularly cycling middle-aged females are significantly less than in young females on the day of the LH surge; (2) determined if icv infusion of VIP rescues LH surge amplitude and/or restores the timing of the LH surge in regularly cycling middle-aged females; and (3) determined if icv infusion of VIP restores the activation of $\mathrm{GnRH}$ neurons, as determined by c-fos co-expression, in middle-aged females.

\section{MATERIALS AND METHODS}

\section{ANIMALS AND HORMONE ADMINISTRATION}

Young (2-3 months) and middle-aged (retired breeders, 911 months) female Sprague-Dawley rats (Taconic Farms, Germantown, NY, USA) were housed individually and maintained on a 14-h light, 10-h dark cycle (lights on at 0600) with free access to chow and water. Only rats with at least two regular 4-5 day estrous cycles were used. All procedures followed the National Institutes of Health Guide for the Care and Use of Laboratory Rats and were approved by the Institutional Animal Care and Use Committee at the Albert Einstein College of Medicine. All studies conditions were done in parallel. To induce LH surges, estradiol benzoate (EB) and progesterone (P; Steraloids Inc., Newport, RI, USA) were dissolved in peanut oil and administered subcutaneously in a volume of $0.1 \mathrm{ml}$. At 0900 hours 7 days after ovariohysterectomy (OVX) and cannula placement, rats received the first of two daily injections of $2 \mu \mathrm{g}$ of EB. At 0900 hours 2 days after the first EB injection, rats were injected with $500 \mu \mathrm{g}$ of $\mathrm{P}$. This hormone regimen reliably produces LH surges in $75-80 \%$ of OVX female rats (Neal-Perry et al., 2005).

\section{CANNULA PLACEMENT AND JUGULAR VEIN CATHETERIZATION}

For OVX and stereotaxic surgery, rats were anesthetized with intramuscular ketamine/xylazine ( 80 and $4 \mathrm{mg} / \mathrm{kg}$, respectively). After OVX, they were placed in a Kopf stereotaxic apparatus. A 22gage icv guide cannula (Plastics One, Roanoke, VA, USA) was placed into the third ventricle $(\mathrm{A} / \mathrm{P}+0.2 \mathrm{~mm} ; \mathrm{M} / \mathrm{L}+0.0 \mathrm{~mm} ; \mathrm{D} / \mathrm{V}$
$-9.8 \mathrm{~mm}$ relative to Bregma) and plugged with a 26-gage dummy that extended $1 \mathrm{~mm}$ below the guide (Todd et al., 2010). Animals recovered for 6- to 7-days before further manipulations. Correct guide cannula placement was verified by tracking the path of the cannula in brain sections at the time of immunohistochemistry (IHC). Only those rats with correct placement of the icv cannulae were included in data analysis.

An indwelling catheter for serial blood sampling was placed in the jugular vein of anesthetized females 7 days after OVX and stereotaxic surgery as previously described (Neal-Perry et al., 2005). Catheters were kept patent by daily flushing with heparinized saline (50 IU). Blood collection ( $300 \mu \mathrm{l} /$ sample) was initiated 2 days after the first $\mathrm{EB}$ injection starting at the time of the $\mathrm{P}$ injection and then every $2 \mathrm{~h}$ for $12 \mathrm{~h}$. Blood was collected into tubes containing heparinized saline (10 IU), refrigerated overnight, and centrifuged at $10,000 \times g$ for $20 \mathrm{~min}$. Plasma was stored at $-80^{\circ} \mathrm{C}$ until assayed for $\mathrm{LH}$. An equal volume of warmed saline was infused after each blood collection to avoid hypovolemia.

\section{ICV DRUG ADMINISTRATION}

Normal saline was used to dissolve drugs and infused into all control rats. Two days after the first EB injection, the rats were connected to an automatic pump (Bioanalytical System Inc., West Lafayette, IN, USA) and attached to a tether allowing rats to move freely. Twenty micrograms of human VIP peptide $(6 \mathrm{nmol}$; Bachem, CA, USA) or saline (vehicle/control) was infused into the third ventricle of young and middle-aged rats between 1300 and $1600 \mathrm{~h}$ at $2 \mathrm{nmol} / 15 \mu \mathrm{l} / \mathrm{h}$, the time of the $\mathrm{LH}$ surge in young, reproductive-aged females (Neal-Perry et al., 2005).

\section{LH RADIOIMMUNOASSAY}

Plasma LH concentrations were measured in duplicate with rat double-antibody assays reagents provided by the Reproduction Ligand Assay and Analysis Core, General Clinical Research Center, University of Virginia (Charlottesville, VA, USA). The lower limit of the $\mathrm{LH}$ assay was $0.04 \mathrm{ng} / \mathrm{ml}$ and the intra- and inter-assay coefficients of variation were 3.9 and $5.7 \%$, respectively. An LH surge was defined as greater than or equal to a 1.5-fold increase in serum LH levels from baseline for a minimum of two consecutive samples, and surge onset was considered to occur at the first of these samples (Todd et al., 2010). Baseline LH levels are defined by those at the time of $\mathrm{P}$ injection. Only those females who demonstrated an LH surge were included in the data analysis.

\section{HYPOTHALAMIC DISSECTION, RNA PURIFICATION, REVERSE TRANSCRIPTION, AND REAL-TIME PCR FOR VIP}

Independent groups OVX, young $(n=5-7)$, and middle-aged $(n=5-7)$ rats were primed with oil (control/vehicle) or EB and $\mathrm{P}$ as described above. Rats were killed $4 \mathrm{~h}$ after the $\mathrm{P}$ or last oil injection. The hypothalamus was dissected into anterior and posteriors halves (Neal-Perry et al., 2008), snap frozen on dry ice, and stored at $-80^{\circ} \mathrm{C}$ until determination of VIP mRNA levels. DNAfree total RNA was purified using the RNeasy lipid minikit (Qiagen, Valencia, CA, USA) including a deoxyribonuclease step. Reverse transcription (RT) was performed using the high-capacity cDNA RT kit with ribonuclease inhibitor (Applied Biosystems, Foster 
City, CA, USA) using $500 \mathrm{ng}$ of RNA. Gene expression was measured by real-time PCR using TaqMan gene expression assays and master mix (Applied Biosystems) according to the manufacturer's instructions. 18S ribosomal RNA (18S rRNA, Fam probe, reference sequence Hs99999901_s1, context sequence X03205.1) was the endogenous control for VIP (Fam probe, reference sequence Rn01430567_m1; context sequence NM_053991.1). Real-time PCR was performed using an ABI PRISM 7900HT (Applied Biosystems) in simplex conditions using 50 ng of cDNA. Amplified transcripts for VIP were quantified using the comparative threshold cycle method and $18 \mathrm{~S}$ rRNA as normalizer. The fold change in VIP expression was calculated as $2^{-\Delta \Delta C T}$ where $\mathrm{CT}=$ threshold cycle, $\Delta \mathrm{CT}=\mathrm{CT}(\mathrm{VIP})-\mathrm{CT}(18 \mathrm{~S}$ rRNA $), \Delta \Delta \mathrm{CT}=\Delta \mathrm{CT}($ experimental $)-\Delta \mathrm{CT}$ (reference). $\Delta \mathrm{CT}$ (reference) was calculated using the mean of the $\Delta \mathrm{CT}$ for the hypothalamus of OVX controls treated with oil.

\section{IHC FOR GnRH AND c-fos}

As per a modified protocol of Hoffman et al. independent groups of animals were perfused with $4 \%$ paraformaldehyde and $2.5 \%$ acrolein in phosphate buffer ( $\mathrm{pH}$ 6.8) after VIP infusion between 1600 and $1730 \mathrm{~h}$ on the expected day of the LH surge (Hoffman and Le, 2004; Sun et al., 2011). Brains were post-fixed in $4 \%$ paraformaldehyde overnight at $4^{\circ} \mathrm{C}$, and then placed in $30 \%$ sucrose until they sank. This fixative method affords advantages that include improved antigen retrieval and improved signal tonoise ratios. Six sets of coronal sections $(30 \mu \mathrm{m})$ starting at the level of the organum vasculosum of lamina terminalis (Bregma $+0.48 \mathrm{~mm}$ ) and continuing through the medial preoptic area (POA; Bregma $-0.72 \mathrm{~mm}$ ) were collected from each animal, with each set containing every sixth section. Sections were stored in cryoprotectant at $-20^{\circ} \mathrm{C}$ until processed for immunolabeling (Hoffman and Le, 2004).

As previously described (Sun et al., 2011) tissue sections were rinsed in potassium phosphate buffered saline (KPBS, $0.05 \mathrm{M}, \mathrm{PH}$ 7.4) to remove cryoprotectant, incubated in $1 \%$ sodium borohydrate to remove acrolein and then $3 \% \mathrm{H}_{2} \mathrm{O}_{2}$ for 10 min to block endogenous peroxidase activity. Sections were subsequently incubated in KPBS plus 0.04\% Triton-X 100 (KPBS-Tx) and 1\% bovine serum albumin (BSA) for $1 \mathrm{~h}$ at room temperature. Sections were incubated in goat anti-c-fos antibody (1:1000, Santa Cruz Biotechnology Inc., Santa Cruz, CA, USA) in KPBS-Tx and 1\% BSA for $48 \mathrm{~h}$ at $4^{\circ} \mathrm{C}$ next and then incubated in biotinylated anti-goat immunoglobulin G (IgG, 1:600, Vector Laboratories, Burlingame, CA, USA) in KPBS-Tx for $1 \mathrm{~h}$ at room temperature. Finally sections were rinsed and incubated for $1 \mathrm{~h}$ in avidin biotin complex ('Elite' ABC kit, Vector Laboratories). After rinsing in KPBS and $0.175 \mathrm{M}$ sodium acetate, the sections were stained in nickel sulfate $(25 \mathrm{mg} / \mathrm{ml})$ and diaminobenzidine- $\mathrm{HCl}(\mathrm{DAB}, 0.2 \mathrm{mg} / \mathrm{ml})$ in $0.175 \mathrm{M}$ sodium acetate containing $30 \% \mathrm{H}_{2} \mathrm{O}_{2}$ for $10 \mathrm{~min}$ followed by a final rinse in KPBS and sodium acetate. C-fos immunoreactive (ir) neurons were visualized as blue-black in the nuclei of neurons. For colocalization of c-fos in GnRH neurons, the sequence of reactions was repeated, substituting rabbit-anti $\mathrm{GnRH}$ antiserum as the primary antibody (1:5000, LR-5, a generous gift from Dr. R. Benoit, McGill University, Montreal, Canada) for $24 \mathrm{~h}$ at $4^{\circ} \mathrm{C}$. After rinsing, sections were incubated in biotinylated anti-rabbit
IgG (Vector Laboratories) diluted (1:600) in KPBS-Tx for $1 \mathrm{~h}$ at room temperature, rinsed, and reacted with the avidin biotin complex as described above. A mixture of $\mathrm{H}_{2} \mathrm{O}_{2}$ and $\mathrm{DAB}-\mathrm{HCl}$ in Tris (Sigma Aldrich Inc., St. Louis, MO, USA; 0.05 M, pH 7.2) was used as the chromogen to yield a brown staining in the cytoplasm. Sections were mounted onto Superfrost Plus slides (Fisher Scientific, Pittsburgh, PA, USA). After drying overnight, the sections were dehydrated with ascending alcohol concentrations, cleared with xylenes, and coverslipped. A series of tissue sections was treated identically except without primary antibody to control for antibody specificity.

\section{QUANTIFICATION GnRH AND c-fos-IMMUNOPOSITIVE CELLS}

To quantify GnRH and c-fos-ir neurons, five sections of POA in the 1 -in- 6 series were viewed under a microscope (Zeiss Axioversion, Carl Zeiss, Thornwood, NY, USA; Sun et al., 2011). Sections corresponded to Plates 30-35 of the Paxinos and Watson atlas. Cells were considered c-fos-ir if they had blue/black nuclear staining with distinct nuclear boundaries. GnRH-ir cells were counted when the cell body was clearly identified and if they had brown cytoplasmic staining. GnRH neurons expressing c-fos were counted at $40 \times$ magnification; if cells had both brown cytoplasmic and blue/black nuclear staining, they were considered to be double labeled (Figures $\mathbf{3 A - H}$ ). Cell counting was performed by two counters blinded to treatment (inter-rater variation $<10.5 \%$ ) and average cell counts reported. Total $\mathrm{GnRH}$ and c-fos neurons as well as the percent of $\mathrm{GnRH}$ neurons expressing c-fos were calculated.

\section{STATISTICAL ANALYSIS}

Data are expressed as mean \pm SEM. The area under the curve (AUC) for total LH release was calculated using Sigma Plot 10.0 (Systat Software, Inc., Chicago, IL, USA). A mixed design two-way ANOVA was used to determine the effect of time (repeated measure) and VIP (independent measure) on LH release. Two-way ANOVA (age $\times$ treatment) was used to determine differences in VIP mRNA and in total LH, GnRH, and c-fos cell numbers and percent of GnRH neurons expressing c-fos. $P<0.05$ was considered statistically significant. Non-parametric testing was used when data were not normally distributed. Bonferroni or Newman-Keuls post hoc tests were performed as appropriate.

\section{RESULTS}

\section{LH SURGES AND HYPOTHALAMIC VIP mRNA EXPRESSION IN YOUNG AND MIDDLE-AGED RATS}

The EB and P-induced $\mathrm{LH}$ surge is delayed and attenuated in middle-aged rats compared to young rats (Figures 1A,B). Previous studies suggest that circadian-related changes in VIP cells of the SCN regulate the onset and peak of $\mathrm{LH}$ release in young rats (Colwell et al., 2003). Moreover, in situ hybridization suggests that old, irregularly cycling middle-aged, and persistent diestrus females have reduced VIP mRNA levels in the SCN and the POA on the day of the LH surge. To determine if hormone treatment affects hypothalamic VIP mRNA expression in regularly cycling, middle-aged females, we quantified VIP mRNA expression levels in the hypothalamus of a separate group of OVX control and $\mathrm{EB}+\mathrm{P}$-primed young and middle-aged females by real-time PCR. Neither age nor hormone treatment significantly affected 

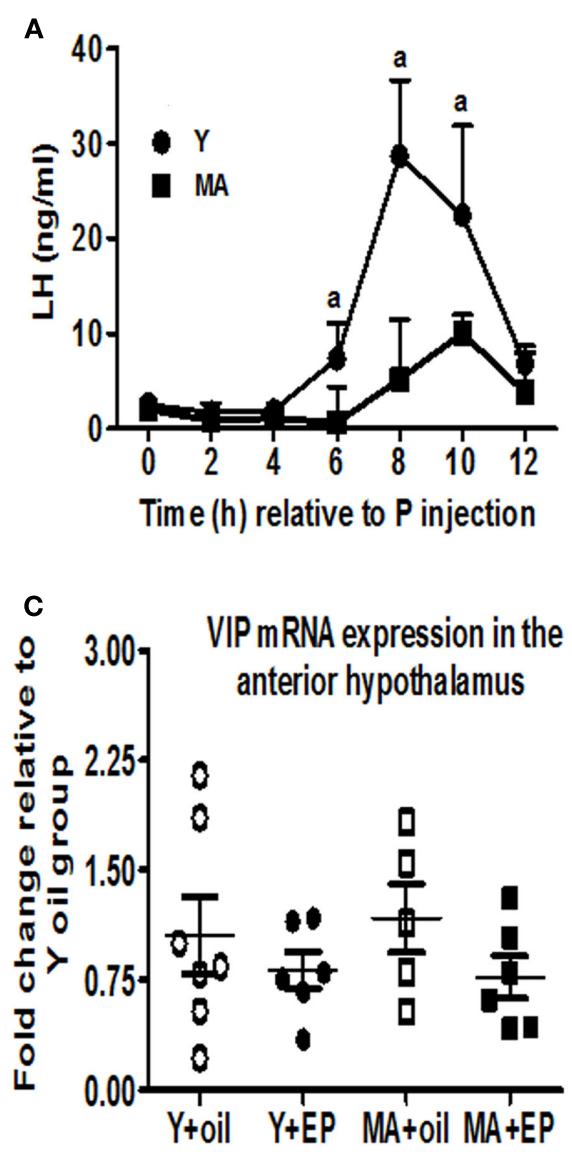

FIGURE 1 | Hypothalamic VIP mRNA expression is not reduced in regularly cycling, middle-aged females with delayed and attenuated $\mathbf{L H}$ surges. OVX young $(Y ; n=6)$ and middle-aged $(M A ; n=6)$ female rats received two daily doses of $E 2$ benzoate $(E: 2 \mu \mathrm{g})$ and one injection of progesterone (P: $500 \mu \mathrm{g}$ ) on the day of serum collection, or vehicle (oil). Serial blood sampling started at the time of $P$ injection and continued every $2 \mathrm{~h}$ for $12 \mathrm{~h}$. Time 0 represents the time of the $P$ injection. Separate rats were used in RT-PCR experiments and were killed $52 \mathrm{~h}$ after the first injection of oil or $\mathrm{E}$

total VIP mRNA levels in the anterior or posterior hypothalamus (Figures 1C,D).

\section{ICV INFUSION OF VIP RESTORES LH SURGE AMPLITUDE AND ADVANCES PEAK RELEASE OF LH IN MIDDLE-AGED RATS}

OVX, EB + P-primed rats were infused continuously with saline or VIP ( $6 \mathrm{nmol}$ total dose) between 1300 and $1600 \mathrm{~h}$ on the day of the LH surge. There was a significant interaction between age and VIP treatment on total $\mathrm{LH}$ and peak LH release $(P<0.01)$. Middleaged females infused with VIP exhibited a greater than twofold increase in total (Figure 2C; $P<0.01$ ) and peak LH (Figure 2E; $P<0.01)$ release compared to middle-aged controls infused with saline. Moreover, VIP infusion rescued peak and total LH release in middle-aged females to levels that were equivalent to young control females (Figures 2A-C,E). VIP infusion did not advance the onset of the LH surge (Figure 2D); however, the time of peak LH release was significantly advanced in middle-aged females infused with VIP (Figure 2F; $P<0.03$ ).
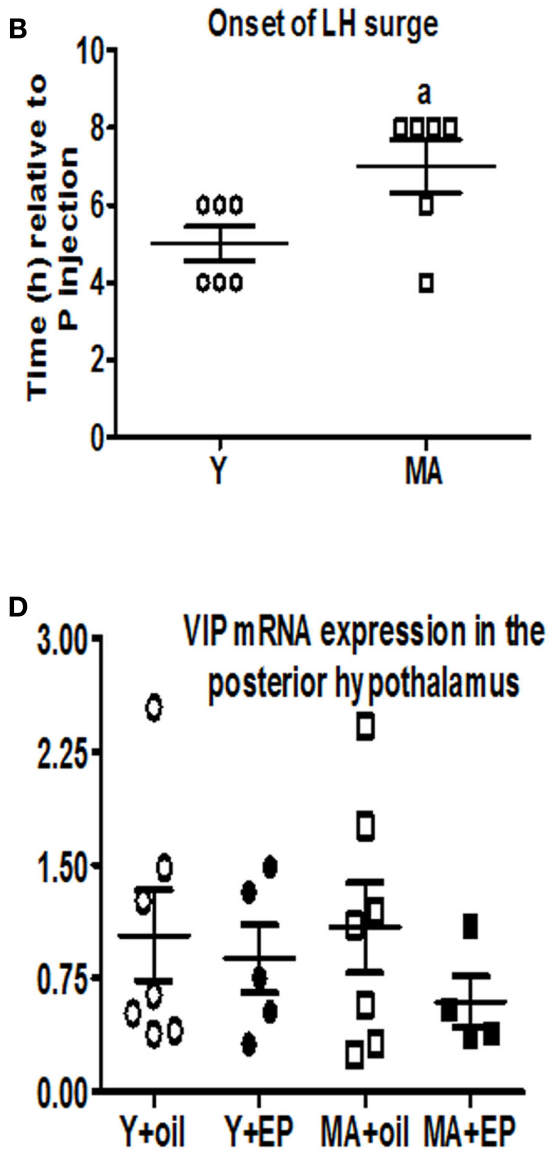

Data are expressed as mean \pm SEM. (A) LH surge in young (O) and middle-aged females ( $\mathbf{\square}$ ) infused with icv saline. (B) Scatter plots of LH surge onset in young $(\mathrm{O})$ and middle-aged females $(\square)$ infused with icv saline. (C) Scatter plots of VIP mRNA expression levels in the anterior hypothalamus of young $(0, \mathbf{0} ; n=6-7)$ and middle-aged $(\square, \mathbf{\square} ; n=5-6)$ rats primed with $E+P(\mathbf{Q}, \mathbf{\square})$ or oil $(O, \square)$. (D) Scatter plots of VIP mRNA expression levels in the posterior hypothalamus of young $(O, \mathbf{0} ; n=5-7)$ and middle-aged $(\square, \mathbf{\square}$ $n=4-7)$ rats primed with $\mathrm{E}+\mathrm{P}(\boldsymbol{\bullet}, \mathbf{\square})$ or oil $(0, \square) .{ }^{\text {a }} P<0.05$ vs. middle-aged.

\section{ICV INFUSION OF VIP ATTENUATES AND DELAYS THE LH SURGE IN YOUNG RATS}

Young females infused with VIP had attenuated peak LH levels $(P<0.05)$ and released approximately $2 / 3$ less total $\mathrm{LH}(P<0.01)$ than young controls (Figures $2 \mathrm{~A}, \mathbf{E})$. Peak LH release $(P<0.05)$ and the onset of the LH surge $(P<0.05)$ were significantly delayed in VIP-infused young rats (Figures 2D,F).

\section{VIP INFUSION INCREASES THE PERCENT OF GRRH NEURONS EXPRESSING c-fos AND NUMBERS OF c-fos-ir NEURONS IN THE POA OF MIDDLE-AGED FEMALES}

To determine if icv infusion of VIP increased the number of activated $\mathrm{GnRH}$ neurons, we quantified the percent of $\mathrm{GnRH}$ neurons expressing c-fos, a marker of neuronal activation, in hormoneprimed middle-aged females infused with VIP. The number of GnRH neurons in middle-aged females infused with VIP or saline was not significantly different (Figure 3J). Similar to our previous study (Sun et al., 2011), approximately $20 \%$ of GnRH neurons 


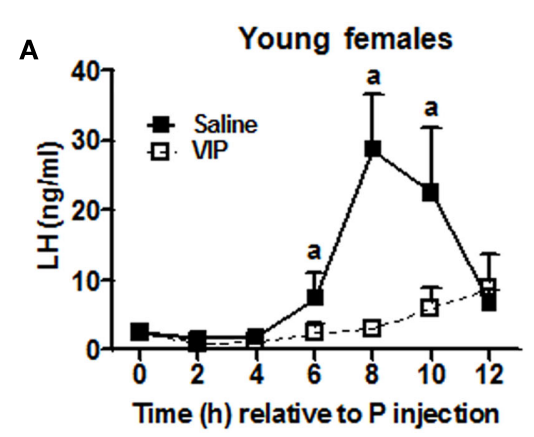

B
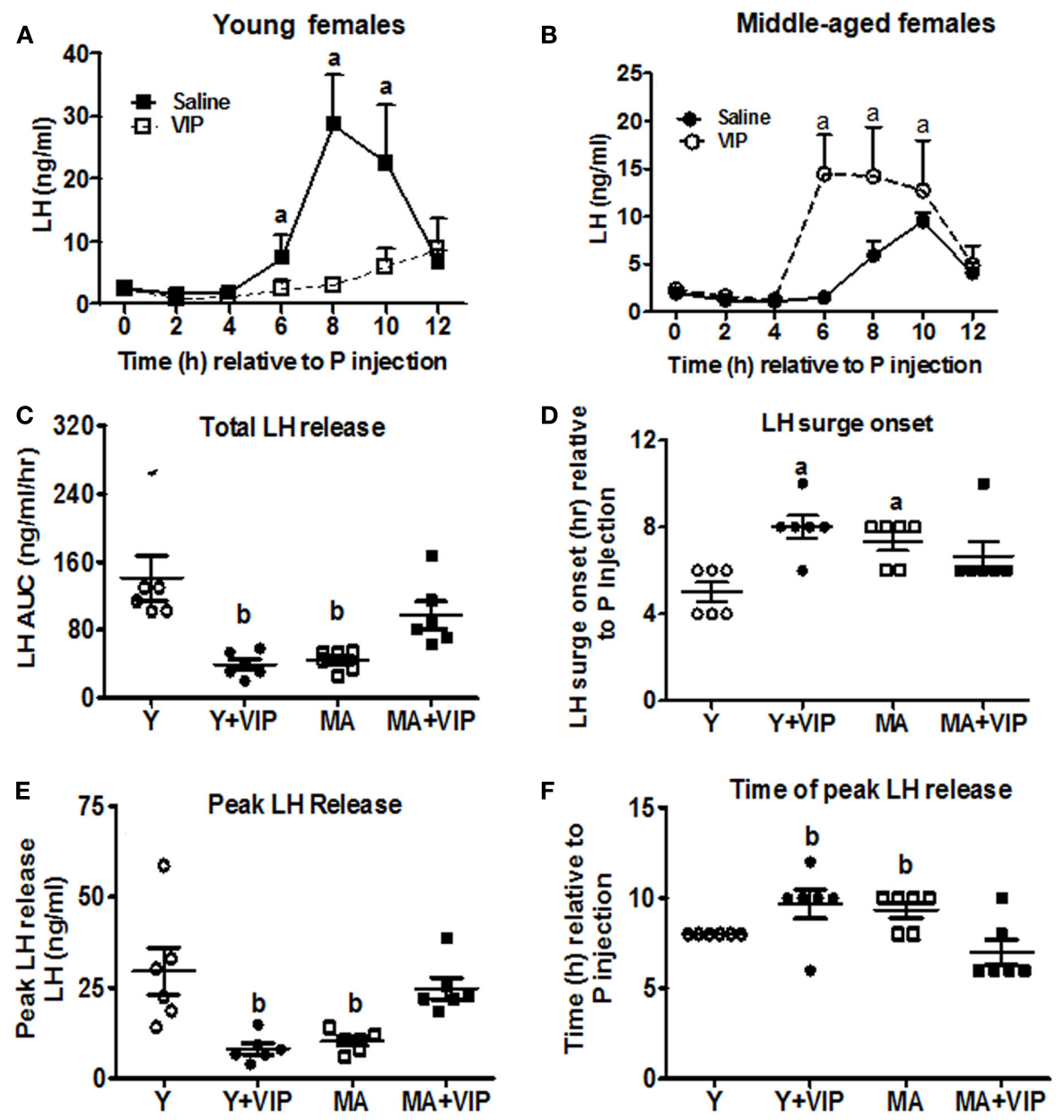

FIGURE 2 | Icv infusion of VIP restores the LH surge in middle-aged females but delays and attenuates the LH surge in young females. Data are expressed as mean \pm SEM. OVX young $(Y ; n=6)$ and middle-aged (MA; $n=6)$ rats were primed with two daily doses of $E(2 \mu \mathrm{g})$ and one injection of $P$ $(500 \mu \mathrm{g})$ on the day of serum collection and infused with saline (control) or VIP $(6 \mathrm{nmol})$ between 1300 and $1600 \mathrm{~h}$. Serial blood sampling started at the time of $\mathrm{P}$ injection and continued every $2 \mathrm{~h}$ for $12 \mathrm{~h}$. To compare the effect of VIP infusion on $\mathrm{LH}$ release in control females, we included the $\mathrm{LH}$ surge data for young and middle-aged, saline infused $E+P$-primed females shown in Figure 1. (A) LH surge in young females infused icr with saline (O) or VIP

in the EB + P-primed middle-aged rats express c-fos (Figure 3I). Middle-aged rats primed with $\mathrm{EB}+\mathrm{P}$ and infused with VIP had a threefold increase $(P<0.01)$ in the number of GnRH neurons expressing c-fos (Figure 3I). Additionally, icv infusion of VIP significantly increased the total number of $\mathrm{c}$-fos-ir neurons in the POA of middle-aged rats by more than threefold $(P<0.001$; Figure 3K).

\section{VIP INFUSION DECREASES THE PERCENT OF GRRH NEURONS EXPRESSING c-fos AND THE NUMBERS OF GnRH-ir NEURONS IN YOUNG FEMALES}

We also determined if VIP infusion modifies the percent of GnRH neurons activated in young females (Figures 3A-H). Consistent with our previous work (Sun et al., 2011), approximately 53\% of $\mathrm{GnRH}$ neurons in young females express c-fos under hormonal conditions that typically induce a robust LH surge (Neal-Perry et al., 2005; Figure 3I). Compared to young control females, infusion of VIP significantly reduced the percent of GnRH neurons expressing c-fos by about 50\% $(P<0.05$; Figure 3I $)$ to levels that were not significantly different than control middle-aged females (Figure 3I). Surprisingly, icv infusion of VIP significantly decreased the number of GnRH-ir neurons $(P<0.05$; Figure 3J). Unlike middle-aged females, icv infusion of VIP in young females did not significantly affect c-fos expression in non-GnRH neurons (Figure 3K).

\section{DISCUSSION}

These data strongly suggest that a critical level of VIP signaling in the brain is important for an appropriately timed and 

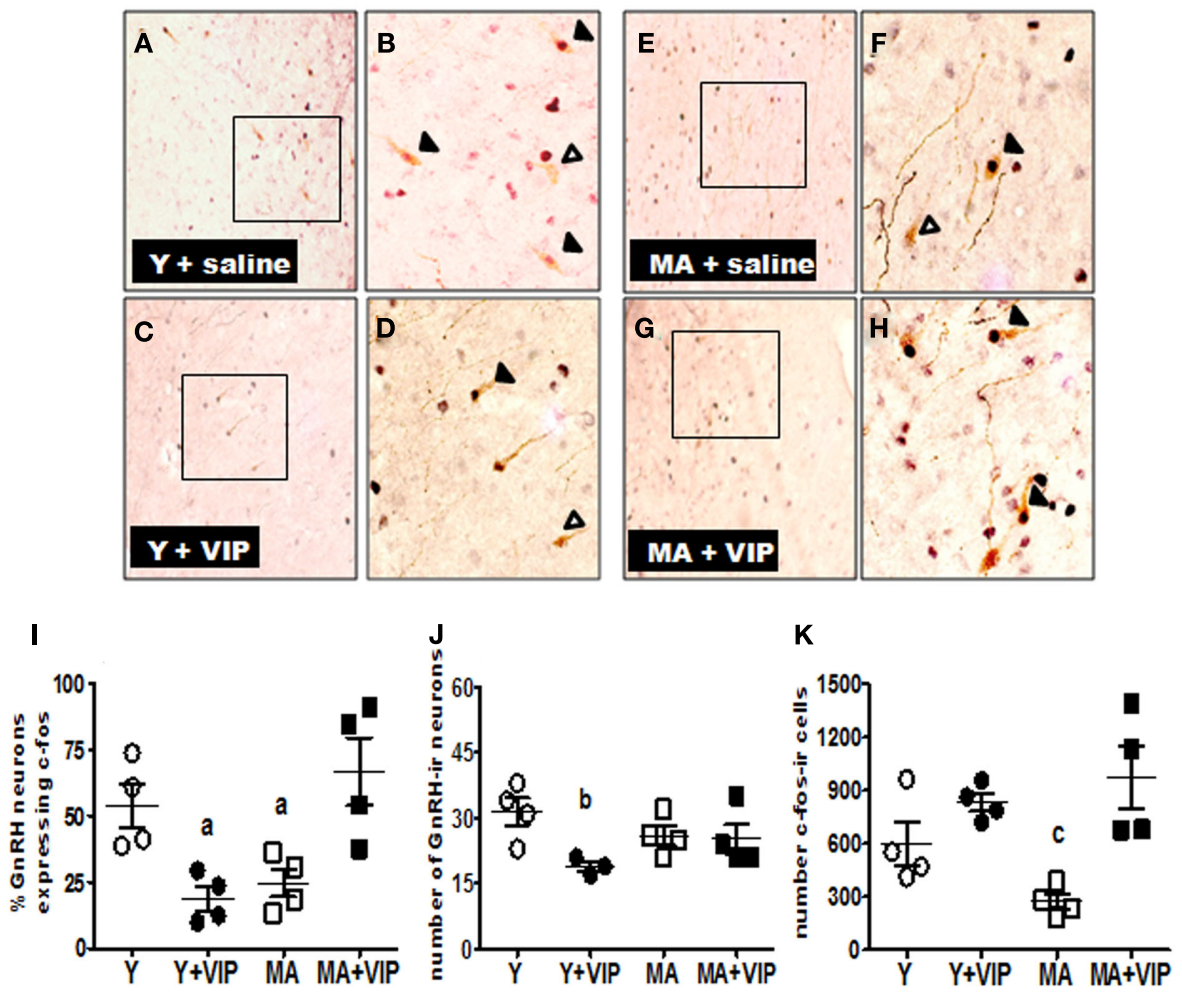

FIGURE 3 | lcv infusion of VIP increased numbers of GnRH/c-fos-ir and c-fos-ir neurons and decreased the number $\mathrm{GnRH}$-ir and GnRH/c-fos-ir in the POA of middle-aged and young females, respectively. Middle-aged (MA; $n=4)$ and young $(Y ; n=4)$ OVX rats primed with $E(2 \mu \mathrm{g})$ and one injection of $P(500 \mu \mathrm{g})$ on the day of serum collection were infused icv with saline (control) or VIP (6 $\mathrm{nmol}$ ) between 1300 and $1600 \mathrm{~h}$ and then perfused between 1600 and $1730 \mathrm{~h}$. Data are presented as mean \pm SEM. Representative sections of double-label immunohistochemistry (20x and $40 \times$ magnification) showing $\mathrm{GnRH}$ neurons (brown cytoplasm) with c-fos-ir nuclei (black) in rats infused with saline $(\mathbf{A}, \mathbf{B}, \mathbf{E}, \mathbf{F})$ or VIP (C,D,G,H). Open arrowhead indicate $\mathrm{GnRH}$

robust LH surge in middle-aged rats. We hypothesized that agerelated LH surge changes result from reduced release of central VIP rather than reduced synthesis of or responsiveness to the peptide. Consistent with our hypothesis, we found that the delayed and attenuated LH surge observed in regularly cycling middle-aged females is not associated with reduced hypothalamic VIP mRNA expression levels. Moreover, icv infusion of VIP in middle-aged, hormone-primed females rescued total and peak $\mathrm{LH}$ and the time of peak $\mathrm{LH}$ release. Icv infusion of VIP also increased the number of GnRH and non-GnRH neurons expressing $\mathrm{c}$-fos to levels significantly greater than control middle-aged rats and equivalent to young controls. Icv infusion of VIP did not advance the onset of the LH surge in middleaged females. Taken together, these findings are consistent with others suggesting that reduced VIP neurosignaling delays and attenuates the LH surge (Krajnak et al., 1998, 2001). They also strongly suggest that age-related changes in the LH surge reflect, in part, reduced release of VIP and not reduced responsiveness of middle-aged females to VIP under estradiol positive feedback conditions. neurons. Closed arrowheads indicate $\mathrm{GnRH}$ neurons expressing c-fos. Scale bars, $10 \mu \mathrm{m}$. (I) Scatter plots of the percent of $\mathrm{GnRH}$ neurons expressing c-fos-ir in POA of young $(O, \mathbf{O})$ and middle-aged $(\square, \boldsymbol{\square})$ rats infused with saline $(\mathrm{O}, \square)$ or $\operatorname{VIP}(\mathbf{O}, \mathbf{\square})$. (J) Scatter plots of the total number of $\mathrm{GnRH}$-ir neurons in the POA of young $(\mathrm{O}, \mathbf{O})$ and middle-aged $(\square, \boldsymbol{\square})$ rats infused with saline $(O, \square) \operatorname{or} \operatorname{VIP}(\boldsymbol{\bullet}, \mathbf{\square})$. (K) Scatter plots of the total number of c-fos-ir cells in the POA of young $(\mathrm{O}, \mathbf{0})$ and middle-ages $(\square, \boldsymbol{\square})$ rats infused with saline $(O, \square) \operatorname{or} \operatorname{VIP}(\boldsymbol{\square}, \mathbf{\square})$. a $P<0.05$ vs. saline infused young and VIP-infused middle-aged rats. ${ }^{\mathrm{b}} P<0.05$ vs. saline infused young females. ${ }^{\mathrm{c}} P<0.05$ vs. saline infused young and young and middle-aged females infused with VIP.

In contrast to its effects in middle-aged females, icv infusion of VIP does not advance the onset or increase the peak amplitude of the LH surge in young rats. Instead we demonstrate that increased brain VIP levels impose an opposite effect on young females. VIP infusion significantly reduced the percent of GnRH neurons expressing c-fos, delayed the onset of the LH surge and attenuated peak LH release in young females, thus creating a LH surge pattern reminiscent of one typically observed in middle-aged females. These data strongly suggest that, a critical level of VIP signaling is required in females to maintain appropriately timed and high amplitude preovulatory LH surges.

\section{VIP mRNA EXPRESSION IN YOUNG AND MIDDLE-AGED HORMONE-PRIMED FEMALES}

Neurons located in the SCN are hypothesized to regulate the circadian signal driving the daily LH surge in rodents (BrownGrant and Raisman, 1977). GnRH neurons express VIP receptors (Smith et al., 2000), and VIP neurons in the SCN are hypothesized to project to $45 \%$ of GnRH neurons and to activate $\mathrm{GnRH}$ neurons in an estradiol- and time-dependent fashion (van der 
Beek et al., 1993; Van der Beek et al., 1997; Christian and Moenter, 2008). Studies using in situ hybridization suggest that reduced expression of VIP mRNA in the SCN correlates with the reduced amplitude and delayed onset of $\mathrm{LH}$ surges in middle-aged rats (Harney et al., 1996; Krajnak et al., 1998). Consistent with these experiments the administration of VIP antiserum or VIP antisense oligonucleotide in young reproductive-aged females delays and attenuates the LH surge (Harney et al., 1996; van der Beek et al., 1999). We used quantitative RT-PCR to determine if age and/or hormone treatment significantly affected total VIP expression in anterior hypothalamus (location of the majority of $\mathrm{GnRH}$ neurons contacted by VIP terminals) or the posterior hypothalamus (location of the SCN and the majority of the VIP synthesizing neurons in this region). To our surprise we did not find a significant age-related difference in anterior or posterior hypothalamic VIP mRNA expression, thereby suggesting age-related changes in the LH surge do not correlate with reduced hypothalamic VIP mRNA levels in middle-aged females that still have regular estrous cycles. These findings differ from prior studies that report reduced VIP mRNA expression in the hypothalamus of irregularly cycling middle-aged and persistent diestrus old females (Krajnak et al., 1998). The main difference in our study and earlier studies is that we determined hypothalamic VIP mRNA levels in regularly cycling females instead of irregularly cycling (Krajnak et al., 1998) or persistent diestrus old females (Krajnak et al., 2001). Thus, it is possible that females with regular estrous cycles have not yet reached a stage when VIP mRNA synthesis declines. Alternatively, it is possible that changes in VIP mRNA expression are localized to the SCN and our technical approach does not detect fine local changes in SCN (Panda et al., 2002). Thus, it is possible that age-related differences in VIP expression in regularly cycling middle-aged females would be detected with microdissection of the SCN.

\section{VIP PROMOTES A HIGH AMPLITUDE LH SURGE AND ACTIVATION OF GnRH NEURONS IN MIDDLE-AGED FEMALES}

Age-related changes in the LH surge correlate with changes in the rhythmic expression of VIP mRNA and reduced VIP mRNA content in the SCN (Krajnak et al., 1998). Additionally, age-related LH surge dysfunction in irregularly cycling middle-aged and persistent diestrus old females is hypothesized to reflect reduced responsiveness to VIP, because reduced numbers of VIP-innervated GnRH neurons express c-fos on the day of the LH surge (Krajnak et al., 1998). Although we did not observe a significant reduction in hypothalamic VIP mRNA levels, it is still possible that age-related changes in the LH surge reflect reduced availability or release of VIP or altered responsiveness to VIP under estrogen positive feedback conditions (Krajnak et al., 2001). To address this question, we infused VIP into the third ventricle of middle-aged hormoneprimed females and assessed onset and time of peak LH release, total and peak LH release, the percent of GnRH and non-GnRH neurons expressing c-fos in the POA. Icv infusion of VIP did not significantly advance the onset of the LH surge in middle-aged females. However, VIP significantly increased total and peak LH release and advanced the time of peak LH release in middle-aged females to levels seen in young controls. These in vivo experiments strongly support the hypothesis that reduced availability of
VIP and not reduced responsiveness to VIP under estradiol positive feedback conditions contributes to the delayed and attenuated LH surge in regularly cycling, middle-aged females. Additionally, because we did not demonstrate an age-related reduction in hypothalamic VIP mRNA levels, reduced availability of VIP most likely reflects reduced VIP release rather than reduced peptide synthesis. This may also explain why significant numbers of GnRH neurons with VIP contacts in middle-aged females fail to express c-fos on the day of the LH surge (Krajnak et al., 2001). Interestingly, although VIP infusion advanced the time of peak LH release, it did not advance LH surge onset. These data suggest that timing of peak LH release and the onset time of the surge may be differentially regulated by VIP or that reduced VIP only partially explains age-related LH surge dysfunction.

Electrophysiological studies suggest that VIP stimulates GnRH neurons (Christian and Moenter, 2008). Consistent with electrophysiological studies, anatomical studies show as much as $60 \%$ of GnRH neurons with VIP contacts express c-fos on the day of the LH surge (Krajnak et al., 2001). Thus, we determined if VIPinduced LH release correlates with increased GnRH or non-GnRH neuronal activation in the POA on the day of the LH surge. Icv infusion of VIP increased the number of c-fos-expressing $\mathrm{GnRH}$ and non-GnRH neurons, thereby strongly suggesting that agerelated LH surge dysfunction involves suboptimal VIP-dependent activation of hypothalamic neurons involved in the induction of the LH surge. Although our studies strongly suggest that VIP affects $\mathrm{LH}$ release in middle-aged rats by activating GnRH neurons, it is possible that the peptide increases LH by modulating GnRH release from axon terminals (Samson et al., 1981). Alternatively, because VIP also significantly increased c-fos expression in non-GnRH neurons, icv infusion of VIP may increase $\mathrm{LH}$ release in middle-aged rats by indirect activation of $\mathrm{GnRH}$ neurons.

The mechanisms resulting in reduced VIP neurotransmission in middle-aged females are unknown. We have demonstrated that female reproductive aging is characterized by reduced glutamatergic and increased GABAergic neurotransmission in the POA (Neal-Perry et al., 2005, 2008). VIP neurons located in the SCN receive glutamatergic afferents from the POA (Kiss et al., 2008). Thus it is possible that reduced availability of VIP peptide results from reduced excitatory afferent input to VIP neurons from glutamatergic neurons located in POA. Several studies have demonstrated that AVP neurosignaling is important for high amplitude LH surges in young reproductive-aged females (Palm et al., 1999; Miller et al., 2006). Our studies do not rule out the possibility that altered AVP neurosignaling also contributes to age-related LH surge dysfunction. Additional studies are required to test these hypotheses.

\section{ADVERSE EFFECTS OF VIP ON ACTIVATION OF GnRH NEURON AND LH RELEASE}

Several studies report that continuous VIP infusion in young reproductive-aged females reduces $\mathrm{LH}$ pulse frequency and blocks the LH surge (Alexander et al., 1985; Akema et al., 1988; Weick and Stobie, 1995). Consistent with other reports we found VIP infusion significantly decreased LH release in young rats (Weick and Stobie, 1992). VIP infusion also attenuated and delayed peak LH 
release and the LH surge onset. Icv infusion of VIP also reduced the number of $\mathrm{GnRH}$ neurons co-expressing c-fos from 54 to $19 \%$. To our surprise, VIP also significantly reduced numbers of GnRH-ir neurons. One interpretation of these data is that VIP reduced GnRH-LH release by reducing GnRH peptide expression and activation of GnRH neurons. The cellular mechanism(s) responsible for this surprising finding is (are) unclear. One other study reported a similar finding in seasonal breeding juncos in which the number of VIP-ir neurons inversely correlated with the number of GnRH-ir neurons; photosensitive (breeding) juncos have a low ratio of VIP-to-GnRH-ir neurons, and photorefractory (non-breeding) juncos have a high ratio of VIP-to-GnRH-ir neurons (Saldanha et al., 1994).

\section{CONCLUSION}

Previous studies in irregularly cycling middle-aged and persistent diestrus females suggest that delayed and attenuated LH surges might result from reduced hypothalamic VIP levels and responsiveness to VIP. This study strongly supports the hypothesis that age-related LH surge dysfunction in regularly cycling middle-aged females most likely reflects reduced VIP release and not abnormal responsiveness to VIP. Considerable evidence suggests age-related changes in the timing and magnitude of the LH surge in regularly

\section{REFERENCES}

Akema, T., Hashimoto, R., and Kimura, F. (1988). Preoptic injection of VIP, but not of secretin or PHI, inhibits $\mathrm{LH}$ and stimulates prolactin secretion in the ovariectomized rat. Brain Res. 441, 367-370.

Alexander, M. J., Clifton, D. K., and Steiner, R. A. (1985). Vasoactive intestinal polypeptide effects a central inhibition of pulsatile luteinizing hormone secretion in ovariectomized rats. Endocrinology 117, 2134-2139.

Brown-Grant, K., and Raisman, G. (1977). Abnormalities in reproductive function associated with the destruction of the suprachiasmatic nuclei in female rats. Proc. R. Soc. Lond. B Biol. Sci. 198, 279-296.

Card, J. P., Fitzpatrick-McElligott, S., Gozes, I., and Baldino, F. Jr. (1988). Localization of vasopressin-, vasoactive intestinal polypeptide-, peptide histidine isoleucineand somatostatin-mRNA in rat suprachiasmatic nucleus. Cell Tissue Res. 252, 307-315.

Christian, C. A., and Moenter, S. M. (2008). Vasoactive intestinal polypeptide can excite gonadotropin-releasing hormone neurons in a manner dependent on estradiol and gated by time of day. Endocrinology 149, 3130-3136.

Colwell, C. S., Michel, S., Itri, J., Rodriguez, W., Tam, J., Lelievre, V., Hu, Z., Liu, X., and Waschek, J. A. (2003). Disrupted circadian rhythms in VIP- and PHI-deficient mice. Am. J. Physiol. Regul. Integr. Comp. Physiol. 285, R939-R949.

Cooper, R. L., Conn, P. M., and Walker, R. F. (1980). Characterization of the LH surge in middle-aged female rats. Biol. Reprod. 23, 611-615.

de la Iglesia, H. O., and Schwartz, W. J. (2006). Minireview: timely ovulation: circadian regulation of the female hypothalamo-pituitarygonadal axis. Endocrinology 147, 1148-1153.

Gerhold, L. M., and Wise, P. M. (2006). Vasoactive intestinal polypeptide regulates dynamic changes in astrocyte morphometry: impact on gonadotropin-releasing hormone neurons. Endocrinology 147, 2197-2202.

Harney, J. P., Scarbrough, K., Rosewell, K. L., and Wise, P. M. (1996). In vivo antisense antagonism of vasoactive intestinal peptide in the suprachiasmatic nuclei causes aging-like changes in the estradiolinduced luteinizing hormone and prolactin surges. Endocrinology 137, 3696-3701.

Hoffman, G. E., and Le, W. W. (2004). Just cool it! Cryoprotectant antifreeze in immunocytochemistry and in situ hybridization. Peptides 25, 425-431.

Kiss, J., Csaki, A., Csaba, Z., and Halasz, B. (2008). Synaptic contacts of vesicular glutamate transporter 2 fibres on chemically identified neurons of the hypothalamic suprachiasmatic nucleus of

cycling middle-aged females is associated with the failure of ovarian steroids to regulate a number of neurotransmitter systems involved in GnRH neuron activation. The cellular mechanism(s) that result in reduced VIP release may reflect age-related reduced responsiveness to estradiol of VIP containing neurons in the SCN. In contrast with findings in middle-aged rats, infusion of VIP in young females attenuates and delays the LH surge, and this is associated with reduced activation and reduced numbers of GnRH-ir neurons. These studies suggest that a critical level of VIP signaling is required for the maintenance of an appropriately timed and robust LH surge.

\section{ACKNOWLEDGMENTS}

We thank Dr. Anne Etgen for her thoughtful comments and review of this manuscript. We also thank Dr. Gloria Hoffman and ZunJu Hu for assistance with GnRH and c-fos immunohistochemistry, Dr. Diane Lebesgue for assistance with RT-PCR, and Dr. R. Benoit for providing the GnRH primary antibody. This research was supported by the Eunice Kennedy Shriver NICHD/NIH through cooperative agreement U54 HD058155 as part of the Specialized Cooperative Centers Program in Reproduction and Infertility Research and by the Department of Obstetrics and Gynecology and Women's Health, Albert Einstein College of Medicine.

the rat. Eur. J. Neurosci. 28, 1760-1774.

Krajnak, K., Kashon, M. L., Rosewell, K. L., and Wise, P. M. (1998). Aging alters the rhythmic expression of vasoactive intestinal polypeptide mRNA but not arginine vasopressin mRNA in the suprachiasmatic nuclei of female rats. J. Neurosci. 18, 4767-4774.

Krajnak, K., Rosewell, K. L., and Wise, P. M. (2001). Fos-induction in gonadotropin-releasing hormone neurons receiving vasoactive intestinal polypeptide innervation is reduced in middle-aged female rats. Biol. Reprod. 64, 1160-1164.

Lederman, M. A., Lebesgue, D., Gonzalez, V. V., Shu, J., Merhi, Z. O., Etgen, A. M., and Neal-Perry, G. (2010). Age-related LH surge dysfunction correlates with reduced responsiveness of hypothalamic anteroventral periventricular nucleus kisspeptin neurons to estradiol positive feedback in middle-aged rats. $\mathrm{Neu}$ ropharmacology 58, 314-320.

Miller, B. H., Olson, S. L., Levine, J. E., Turek, F. W., Horton, T. H., and Takahashi, J. S. (2006). Vasopressin regulation of the proestrous luteinizing hormone surge in wild-type and Clock mutant mice. Biol. Reprod. 75, 778-784.

Neal-Perry, G., Lebesgue, D., Lederman, M., Shu, J., Zeevalk, G. D., and Etgen, A. M. (2009). The excitatory peptide kisspeptin restores the luteinizing hormone surge and modulates amino acid neurotransmission in the medial preoptic area of middleaged rats. Endocrinology 150, 3699-3708.

Neal-Perry, G. S., Zeevalk, G. D., Santoro, N. F., and Etgen, A. M. (2005) Attenuation of preoptic area glutamate release correlates with reduced luteinizing hormone secretion in middle-aged female rats. Endocrinology 146, 4331-4339.

Neal-Perry, G. S., Zeevalk, G. D., Shu, J., and Etgen, A. M. (2008). Restoration of the luteinizing hormone surge in middle-aged female rats by altering the balance of GABA and glutamate transmission in the medial preoptic area. Biol. Reprod. 79, 878-888.

Palm, I. F., Van Der Beek, E. M., Wiegant, V. M., Buijs, R. M., and Kalsbeek, A. (1999). Vasopressin induces a luteinizing hormone surge in ovariectomized, estradiol-treated rats with lesions of the suprachiasmatic nucleus. Neuroscience 93, 659-666.

Panda, S., Antoch, M. P., Miller, B. H., Su, A. I., Schook, A. B., Straume, M., Schultz, P. G., Kay, S. A., Takahashi, J. S., and Hogenesch, J. B. (2002). Coordinated transcription of key pathways in the mouse by the circadian clock. Cell 109, 307-320.

Saldanha, C. J., Deviche, P. J., and Silver, R. (1994). Increased VIP and decreased GnRH expression in photorefractory dark-eyed juncos (Junco hyemalis). Gen. Comp. Endocrinol. 93, 128-136. 
Samson, W. K., Burton, K. P., Reeves, J. P., and McCann, S. M. (1981). Vasoactive intestinal peptide stimulates luteinizing hormone-releasing hormone release from median eminence synaptosomes. Regul. Pept. 2, 253-264.

Smith, M. J., Jiennes, L., and Wise, P. M. (2000). Localization of the VIP2 receptor protein on $\mathrm{GnRH}$ neurons in the female rat. Endocrinology 141, 4317-4320.

Sun, Y., Todd, B. J., Thornton, K., Etgen, A. M., and Neal-Perry, G. (2011). Differential effects of hypothalamic IGF-I on gonadotropin releasing hormone neuronal activation during steroid-induced $\mathrm{LH}$ surges in young and middle-aged female rats. Endocrinology 152, 4276-4287.

Todd, B. J., Merhi, Z. O., Shu, J., Etgen, A. M., and Neal-Perry, G. S. (2010). Hypothalamic insulin-like growth factor-I receptors are necessary for hormone-dependent luteinizing hormone surges: implications for female reproductive aging. Endocrinology 151, 1356-1366.

Tsukahara, S. (2006). Increased Fos immunoreactivity in suprachias- matic nucleus before luteinizing hormone surge in estrogen-treated ovariectomized female rats. $\mathrm{Neu}$ roendocrinology 83, 303-312.

Van der Beek, E. M., Horvath, T. L., Wiegant, V. M., Van den Hurk, R., and Buijs, R. M. (1997). Evidence for a direct neuronal pathway from the suprachiasmatic nucleus to the gonadotropin-releasing hormone system: combined tracing and light and electron microscopic immunocytochemical studies. J. Comp. Neurol. 384, 569-579.

van der Beek, E. M., Swarts, H. J., and Wiegant, V. M. (1999). Central administration of antiserum to vasoactive intestinal peptide delays and reduces luteinizing hormone and prolactin surges in ovariectomized, estrogen-treated rats. $\mathrm{Neu}$ roendocrinology 69, 227-237.

van der Beek, E. M., van Oudheusden, H. J., Buijs, R. M., van der Donk, H. A., van den Hurk, R., and Wiegant, V. M. (1994). Preferential induction of c-fos immunoreactivity in vasoactive intestinal polypeptideinnervated gonadotropin-releasing hormone neurons during a steroid- induced luteinizing hormone surge in the female rat. Endocrinology 134 2636-2644.

van der Beek, E. M., Wiegant, V. M., van der Donk, H. A., van den Hurk, R., and Buijs, R. M. (1993). Lesions of the suprachiasmatic nucleus indicate the presence of a direct vasoactive intestinal polypeptide-containing projection to gonadotrophin-releasing hormone neurons in the female rat. J. Neuroendocrinol. 5, 137-144.

Weick, R. F., and Stobie, K. M. (1992). Vasoactive intestinal peptide inhibits the steroid-induced LH surge in the ovariectomized rat. J. Endocrinol. 133, 433-437.

Weick, R. F., and Stobie, K. M. (1995). Role of VIP in the regulation of LH secretion in the female rat. Neurosci. Biobehav. Rev. 19, 251-259.

Wiegand, S. J., and Terasawa, E. (1982). Discrete lesions reveal functional heterogeneity of suprachiasmatic structures in regulation of gonadotropin secretion in the female rat. Neuroendocrinology 34, 395-404.

Wise, P. M. (1982). Alterations in proestrous $\mathrm{LH}, \mathrm{FSH}$, and prolactin surges in middle-aged rats. Proc. Soc. Exp. Biol. Med. 169, 348-354.

Conflict of Interest Statement: The authors declare that the research was conducted in the absence of any commercial or financial relationships that could be construed as a potential conflict of interest.

Received: 18 November 2011; accepted: 31 January 2012; published online: 22 February 2012.

Citation: Sun Y, Shu J, Kyei K and NealPerry GS (2012) Intracerebroventricular infusion of vasoactive intestinal peptide rescues the luteinizing hormone surge in middle-aged female rats. Front. Endocrin. 3:24. doi: 10.3389/fendo.2012.00024 This article was submitted to Frontiers in Genomic Endocrinology, a specialty of Frontiers in Endocrinology.

Copyright (C) 2012 Sun, Shu, Kyei and Neal-Perry. This is an open-access article distributed under the terms of the Creative Commons Attribution Non Commercial License, which permits noncommercial use, distribution, and reproduction in other forums, provided the original authors and source are credited. 